\title{
The Relationship Between Alcohol Consumption and Unprotected Sex Among Known HIV-discordant Couples in Rwanda and Zambia
}

\author{
Matthew E. Coldiron · Rob Stephenson · Elwyn Chomba • \\ Cheswa Vwalika · Etienne Karita · Kayitesi Kayitenkore • \\ Amanda Tichacek · Leia Isanhart · Susan Allen • \\ Alan Haworth
}

Published online: 30 January 2008

(C) Springer Science+Business Media, LLC 2008

\section{Erratum to: AIDS Behav}

\section{DOI 10.1007/s10461-007-9304-x}

Please note that the following section was inadvertently omitted from the article.

\begin{abstract}
Acknowledgements This study has been funded in whole or in part with federal funds from the US National Institutes of Health, under grants RO1 HD 40125, RO1 MH 66767, RO1 AI 40951, U2 GPS 000758, the Fogarty AIDS International Training and Research Program (AITRP) FIC 2D43 TW001042, the Social \& Behavioral Core of the Emory Center for AIDS Research (CFAR) P30 AI050409, and the International AIDS Vaccine Initiative (IAVI). Appreciated is expressed to the staff and study participants of the Rwanda Zambia HIV Research Group.
\end{abstract}

The online version of the original article can be found under doi:10.1007/s10461-007-9304-x.

\footnotetext{
M. E. Coldiron · C. Vwalika · E. Karita - K. Kayitenkore ·

A. Tichacek $\cdot$ L. Isanhart $\cdot$ S. Allen

Rwanda Zambia HIV Research Group, Rollins School of Public

Health, Emory University, Atlanta, GA, USA

R. Stephenson $(\bowtie) \cdot A$. Tichacek $\cdot$ S. Allen

Hubert Department of Global Health, Rollins School of Public Health, Emory University, 1518 Clifton Road, NE, Atlanta, GA, USA

e-mail: rbsteph@sph.emory.edu

E. Chomba

University Teaching Hospital School of Medicine, University of

Zambia, Lusaka, Zambia

C. Vwalika

Zambia Emory HIV Research Project, Lusaka, Zambia

E. Karita $\cdot$ K. Kayitenkore

Project San Francisco, Kigali, Rwanda

A. Haworth

The Ministry of Health Counseling Services Unit, Chainama Hills Hospital \& Department of Psychiatry, University of

Zambia School of Medicine, Lusaka, Zambia
} 